\title{
DINÂMICA DE FUNDO DA ENSEADA DO FLAMENGO, UBATUBA, BRASIL, INFERIDA A PARTIR DA DISTRIBUIÇÃO ESPACIAL, MORFOMETRIA E TAFONOMIA DE FORAMINÍFEROS
}

\author{
RAFAELA BONFANTE LANÇONE, WÂNIA DULEBA, \\ Laboratório de Micropaleontologia, Instituto de Geociências, USP, \\ Rua do Lago, 562, 05508-080, São Paulo, SP, Brasil.rafaelabl@gmail.com,waduleba@uol.com.br
}

MICHEL M. MAHIQUES

Depto. Oceanografia Física, Química e Geológica, Instituto Oceanográfico, USP, Praça do Oceanográfico, 191, 05508-900, São Paulo, SP, Brasil.mahiques@usp.br

\begin{abstract}
RESUMO - Este estudo analisa a distribuição, a morfometria e a tafonomia das carapaças de foraminíferos da enseada do Flamengo (Ubatuba, SP) e avalia sua distribuição espacial a partir da hidrografia e dos parâmetros sedimentológicos atuantes na plataforma interna. A densidade populacional e a diversidade de espécies são maiores na região leste que nas regiões central e oeste. Espécies bioindicadoras de Água Costeira dominam em toda a enseada e, entre estas, dominam as bioindicadoras de ambiente rico em matéria orgânica. Espécies bioindicadoras de Água Tropical são raras, mas são encontradas vivas na desembocadura da enseada e na região nordeste, sugerindo a entrada de massas de água vindas da plataforma externa, alcançando as partes mais internas da enseada, em direção ao continente. As carapaças de tamanho médio (250 - $125 \mu \mathrm{m})$ dominam em toda a baía. As carapaças grandes $(250-500 \mu \mathrm{m})$, apesar de serem subordinadas, são abundantes nas regiões central e leste, enquanto as pequenas $(<125 \mu \mathrm{m})$ são raras na desembocadura, aumentando em número em direção ao continente. O percentual de carapaças fragmentadas é, em geral, baixo, aumentando apenas na zona de rebentação da praia da Enseada, enquanto as corroídas ocorrem em toda a enseada. Carapaças preenchidas com monossulfeto de ferro são normalmente encontradas em áreas confinadas, enquanto carapaças limonitizadas ocorrem próximas à desembocadura. Tais resultados permitem concluir que a enseada do Flamengo é um ambiente de moderada energia hidrodinâmica, que diminui gradualmente em direção ao continente, desde a desembocadura. Com exceção da praia, as áreas mais internas da enseada caracterizam subambientes com baixa energia deposicional e circulação restrita.
\end{abstract}

Palavras-chave: foraminíferos, circulação de fundo, plataforma interna, morfometria, tafonomia.

ABSTRACT - BOTTOM DYNAMIC OF ENSEADA DO FLAMENGO, UBATUBA, BRAZIL, BASED ON SPATIAL DISTRIBUTION, MORPHOMETRY AND TAPHONOMY OF FORAMINIFERA. This study analyzes the distribution, morphometry and taphonomy of the tests of foraminifera in Flamengo Bay, Ubatuba, $\mathrm{SP}$, Brazil, and assesses their spatial variations as related to hydrographic and sedimentological parameters of the shelf. The eastern area presents higher quantity and number of foraminifera species than in the western and central areas. Indicator species of Coastal Water dominate the whole bay. Among these, the organic matter indicators are dominant. Tropical water indicator species are rare, but they are found alive at the mouth of the bay and in the northeastern area. This suggests that water masses enter from the outer platform and spread into the inner parts of the bay. Medium-sized tests $(250-125 \mu \mathrm{m})$ dominate the whole bay. Large tests $(250-500$ $\mu \mathrm{m})$, despite being subordinate to medium-sized ones, are abundant in the central and eastern areas. Small tests $(<125 \mu \mathrm{m})$ are rare at the mouth but increase in number towards the inner areas. Percentages of fragmented carapaces are generally low, but they are higher in the breaker zone of Enseada Beach. Eroded carapaces are found throughout the bay. Tests filled with iron monosulphides are commonly found in the confined areas of the bay and limonitized tests ones are found near the mouth. On the basis of these results, it is concluded that Flamengo Bay is an environment of moderate hydrodynamic energy, which decreases gradually from the mouth towards the mainland. The inner areas are sub-environments with low depositional energy (restricted circulation), except for Enseada Beach.

Key words: foraminifera, sedimentological and hydrodynamic circulation, inner platform, morphometry, taphonomy. 


\section{INTRODUÇÃO}

Foraminíferos bentônicos são importantes ferramentas utilizadas em estudos de circulação marinha ou estuarina. A ocorrência ou a ausência de espécies de diferentes intervalos batimétricos e/ou indicadoras de águas frias ou quentes auxiliam a detectar a entrada e saída das massas de águas na região costeira, na plataforma e no talude (Schnitker, 1974; Murray, 1991; Debenay \& Guilou, 2002). Foraminíferos também são bons indicadores da dinâmica de fundo dos sistemas bentônicos, pois a composição das associações e a morfologia das carapaças são reflexos do padrão hidrodinâmico local (Scott et al., 2001). Enquanto espécies da epifauna são geralmente características de locais ricos em oxigênio (Bernhard, 1986; Murray, 1991), Pseudononion spp., Buliminella elegantissima, Bulimina marginata, Fursenkoina pontoni são bons exemplos de espécies que ocorrem em ambiente redutor, rico em matéria orgânica (Seiglie, 1968). Quanto à morfologia, os formatos, a relação superfície/volume das carapaças e a densidade de poros estão diretamente relacionados com o tipo de ambiente onde vivem (Hendrix, 1958). Portanto, a partir da ocorrência de determinadas espécies e de certas feições morfológicas nas carapaças, pode-se diagnosticar locais com diferentes graus de circulação de fundo.

Além da análise morfológica, o estudo tafonômico das carapaças permite evidenciar várias outras informações a respeito da circulação de fundo (como revisão, ver Martin, 1999a, 1999b). Carapaças corroídas, pequenas, frágeis, preenchidas por monossulfeto ou sulfeto de ferro são indicadoras de ambiente redutor e/ou ambiente subsaturado de carbonato de cálcio (Alexandersson, 1979; Berger, 1979). Carapaças robustas, limonitizadas, que apresentam sinais de abrasão por desgaste mecânico indicam ambiente com alta energia hidrodinâmica (Hallock et al., 1986; Yordanova \& Hohenegger, 2002). Portanto, estudos sobre padrões de distribuição das associações de foraminíferos atuais, integrados a dados morfológicos e tafonômicos das carapaças, permitem aprofundar a compreensão da dinâmica sedimentar de vários tipos de ambientes. Além da aplicação ambiental, esses dados são importantes subsídios para estudos de reconstituição paleoambiental.

O presente trabalho tem por objetivo verificar os efeitos oceanográficos e dos padrões de sedimentação sobre a estrutura das associações de foraminíferos e a morfologia de suas carapaças. Para atingir estes objetivos serão, portanto, realizadas análises composicionais das associações, bem como morfológicas e tafonômicas das carapaças.

\section{ÁREA DE ESTUDO}

A área de estudo situa-se na enseada do Flamengo, Ubatuba, SP, $\left(23^{\circ} 29^{\prime} 42^{\prime \prime}\right.$ a $23^{\circ} 31^{\prime} 30^{\prime \prime} \mathrm{S} / 45^{\circ} 05^{\prime}$ a $\left.45^{\circ} 07^{\prime} 30^{\prime \prime} \mathrm{W}\right)$ (Figura 1). A enseada do Flamengo é rasa, com profundidade máxima de $14 \mathrm{~m}$, ocupando uma superfície de aproximadamente $18 \mathrm{~km}^{2}$, com largura média $2,5 \mathrm{~km}$ e abrindo-se diretamente ao mar. A enseada é orientada na direção norte- sul, tendo, ao fundo, uma extensa praia a nordeste, denominada praia da Enseada e duas pequenas baías: saco do Perequê Mirim, situado ao norte, e o saco da Ribeira, a noroeste (Figura 1).

A enseada do Flamengo é um ambiente semiconfinado, cujo padrão de circulação caracteriza-se pela entrada de correntes vindas do sul, pelo lado ocidental da enseada. Estas correntes, após margearem a costa ocidental, bifurcam-se, indo para o saco da Ribeira e para a costa oriental (Magliocca $\&$ Kutner, 1965). Esse padrão de circulação condiciona a distribuição dos sedimentos de superfície de fundo, havendo deposição de sedimentos mais grossos na costa ocidental e sedimentos mais finos no lado oriental da enseada. A maioria dos sedimentos é de natureza lamo-arenosa, onde os termos mais finos são encontrados na porção mais interna do saco da Ribeira (Mahiques, 1992).

A rede de drenagem local é constituída por pequenos cursos de água e principalmente pelo rio Perequê Mirim. Esta rede geralmente não contribui com volume apreciável de água. Entretanto, durante épocas de maior pluviosidade, há aporte de grande quantidade de fragmentos vegetais e sedimentos continentais (Mahiques, 1992).

\section{MATERIAL E MÉTODOS}

Foram estudadas 10 amostras de sedimento superficial, coletadas com pegador tipo Petersen, a bordo do barco de pesquisa Veliger II, em outubro de 1986 (Figura 1). Para a determinação dos foraminíferos contidos no sedimento, o material foi fixado em álcool $70 \mathrm{GL}$ e corado com rosa de bengala (Walton, 1952) no momento da coleta. Deste material fixado e corado, foi retirada a alíquota de $10 \mathrm{~cm}^{3}$, que foi peneirada a úmido em duas peneiras: 0,500 e 0,062 mm (Schröder et al., 1987). As frações retidas nas peneiras foram secas e submetidas à análise densimétrica por flutuação-afundamento em tricloroetileno (Scott et al., 2001), visando separar os foraminíferos do sedimento.

Uma vez separadas, todas as carapaças de foraminíferos, independente de tamanho ou grau de fragmentação, foram triadas, fixadas (com goma adragante) em lâminas de fundo escuro (porta-foraminíferos), identificadas e contadas. Determinadas amostras foram subamostradas, por possuírem valor muito elevado de espécimes (mais de 200 espécimes).

A classificação genérica dos foraminíferos baseou-se em Loeblich \& Tappan $(1964,1988)$ e a classificação em nível de espécie foi feita a partir de Boltovskoy et al. (1980), de pranchas de trabalhos realizados na região de Ubatuba (Duleba, 1993) e nos exemplares da coleção micropaleontológica do IGcUSP.

Após a etapa de identificação taxonômica foram elaborados mapas: (i) dos principais parâmetros populacionais (dados de densidade e riqueza); (ii) das porcentagens das subordens Rotaliina, Miliolina e Textulariina; e (iii) de distribuição de espécies bioindicadoras, baseando-se nos dados apresentados em Boltovskoy (1958) e Duleba et al. (2005). A partir destes estudos, foram definidos os seguintes balizadores para a determinação do tipo de água e dos 


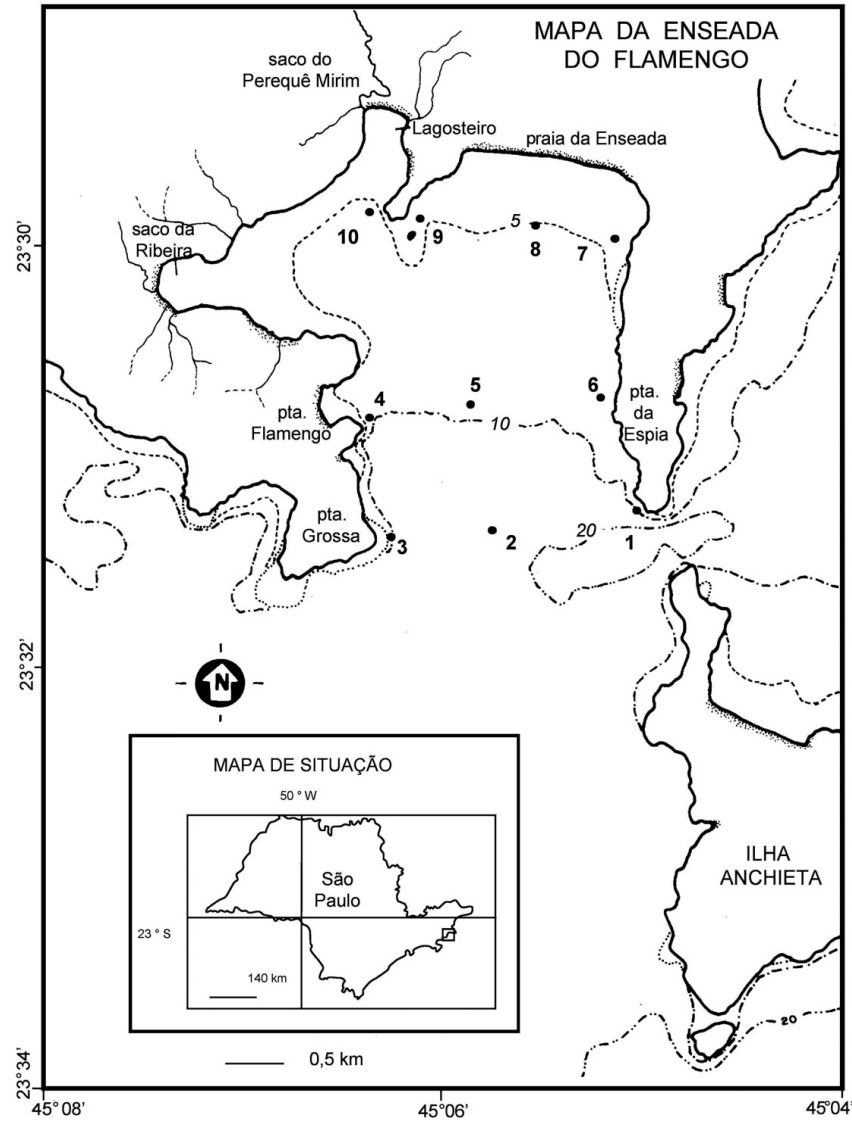

Figura 1. Mapa da enseada do Flamengo, em Ubatuba, com os pontos de amostragem.

Figure 1. Map with location of stations in Flamengo Bay, in Ubatuba with collecting stations.

subambientes presentes na enseada do Flamengo: (i) a presença de Ammonia spp., Cribroelphidium spp. e Pararotalia cananeiaensis como bioindicadores típicos de Água Costeira; (ii) a presença de Bolivina spp., Buliminella elegantissima, Fursenkoina pontoni e Pseudononion spp. como bioindicadores de Água Costeira e de ambientes ricos em matéria orgânica; (iii) a presença de espécies das famílias Cibicididae, Discorbidae, Rosalinidae e Galvenellidae como bioindicadores de Água Costeira e de ambientes com energia hidrodinâmica moderada a forte; (iv) a presença de Angulogerina angulosa, Buccela peruviana f. campsi, Cassidulina crassa e Globigerina bulloides como bioindicadores de Água Central do Atlântico Sul; e (v) a presença de Canepaia brasiliensis, Bulimina spp,. Globigerinoides rubber, Sigmoilopsis schlumbergeri, Uvigerina spp., como bioindicadores da Água Tropical. Nos mapas das espécies bioindicadoras, adotaram-se as seguintes categorias, segundo o percentual de presença nos subambientes amostrados: (i) dominante (> 50\%); (ii) subdominante $(49-25 \%)$; (iii) acessória $(24-5 \%)$; e (iv) $\operatorname{rara}(<5 \%)$.

Determinadas espécies foram selecionadas, metalizadas em ouro e fotografadas em microscópio eletrônico de varre- dura, para ilustrar a microfauna da enseada do Flamengo. Posteriormente, todas as carapaças dos foraminíferos foram fotografadas em câmara digital, acoplada em microscópio estereoscópio. A partir das imagens digitais, foram obtidas medidas morfométricas, através do analisador de imagens Leica QWin 550 IW. Uma vez feitas as análises morfométricas, as carapaças medidas foram divididas em pequenas $(<125$ $\mu \mathrm{m})$, médias $(125-250 \mu \mathrm{m})$, grandes $(250-500 \mu \mathrm{m})$ e muito grandes $(>500 \mu \mathrm{m})$.

Análises tafonômicas foram também realizadas, quantificando o número de carapaças (i) preenchidas por monossulfeto de ferro ou matéria orgânica particulada, (ii) impregnadas por óxido de ferro, (iii) inteiras (i.e., sem vestígios de abrasão mecânica ou corrosão química), e (iv) parcial e totalmente fragmentadas, em amostras de $10 \mathrm{cc}$ de sedimento. Para se detectar corrosão química e/ou presença de bioerosão nas carapaças, foi necessário o uso de microscópio eletrônico de varredura. Para isto, 85 exemplares das 10 amostras foram recobertos com carbono e fotografados. O uso do carbono foi adotado para se obter mais contraste nas imagens digitais.

\section{RESULTADOS}

\section{Composição faunística - Associação total (vivos e mortos)}

Foram identificadas 32 espécies de foraminíferos (Tabela 1; Figura 2). As maiores densidades populacionais foram encontradas na desembocadura e no lado leste da enseada (446 a $1.621 \mathrm{ind} / 10 \mathrm{cc}$ ) (Figura 3A). Os locais mais ricos em espécies estão situados no lado leste ( 23 a 28 espécies) e na região do Lagosteiro (25 espécies) (Figura 3B). Os rotalíneos são as formas dominantes, variando de 70 a $98 \%$ do total das amostras. Os miliolíneos tendem ser mais abundantes na parte central, ao passo que os textularíneos são praticamente ausentes (Figura 3D-E).

De acordo com o mapa de distribuição (Figura 4), constatase que não há uma espécie dominante na enseada do Flamengo. Há somente espécies subdominantes, acessórias ou raras. De modo geral, as subdominantes são Bolivina, e/ou espécies das famílias Cibicidae, Discorbidae, Rosalinidae. As Bolivina spp., por exemplo, são mais abundantes nas porções sudoeste (estações 3 e 4), central (estações 2 e 5) e leste (estações 1,6 e 7). Já as espécies típicas da epifauna são mais numerosas nas imediações do Lagosteiro e na estação 5 (Figura 4E).

Dentre as espécies acessórias, ocorrem espécies do gênero Cribroelphidium e bioindicadoras de ambiente rico em matéria orgânica (Buliminella elegantissima, Fursenkoina pontoni e Pseudononion spp.). As primeiras estão mais concentradas na região do Lagosteiro (estações 10), enquanto que o segundo grupo tende a ser mais abundante nas pontas do Flamengo e Grossa (estações 4 e 3 , respectivamente) e próximo ao boqueirão da ilha Anchieta (estação 1).

As demais espécies representadas na Figura 4 são raras ou podem ser acessórias, em determinadas estações. Pararotalia cananeiaensis, bem como as espécies indicadoras de água de plataforma externa (Uvigerina spp., Siphogenerina raphanus, 
Tabela 1. Freqüência relativa dos foraminíferos encontrados na enseada do Flamengo em outubro de 1986. FA, fração analisada; I, indivíduos; $\mathbf{n}$, número de espécies; $\mathbf{V}$, porcentagem de vivos; $\mathbf{T}$, porcentagem total. Asterisco = jovens de rotaliíneos.

Table 1. Relative abundance of foraminifera species of Flamengo Bay, in October, 1986. FA, analyzed fraction; I, individuals; $\mathbf{n}$, number of species; V, percentage of alive specimens; $\mathbf{T}$, percentage of total specimens. Asterisk = young rotaliines.

\begin{tabular}{|c|c|c|c|c|c|c|c|c|c|c|c|c|c|c|c|c|c|c|c|c|}
\hline \multirow{6}{*}{$\begin{array}{l}F A 0,062 \mathrm{~mm} \\
1 / 10 \mathrm{cc} \\
n\end{array}$} & \multicolumn{20}{|c|}{ ESTAÇÃO/STATION } \\
\hline & \multicolumn{2}{|c|}{1} & \multicolumn{2}{|c|}{2} & \multicolumn{2}{|c|}{3} & \multicolumn{2}{|c|}{4} & \multicolumn{2}{|c|}{5} & \multicolumn{2}{|c|}{6} & \multicolumn{2}{|c|}{7} & \multicolumn{2}{|c|}{8} & \multicolumn{2}{|c|}{9} & \multicolumn{2}{|c|}{10} \\
\hline & \multicolumn{2}{|c|}{$1 / 32$} & \multicolumn{2}{|c|}{$1 / 16$} & \multicolumn{2}{|c|}{$1 / 16$} & \multicolumn{2}{|c|}{$1 / 16$} & \multicolumn{2}{|c|}{$1 / 16$} & \multicolumn{2}{|c|}{$1 / 16$} & $1 /$ & 16 & $1 /$ & 16 & $1 /$ & /8 & & $1 / 8$ \\
\hline & 64 & 1621 & 10 & 813 & 5 & 498 & 13 & 248 & 9 & 70 & 2 & 464 & 18 & 446 & 4 & 315 & 1 & 142 & 5 & 306 \\
\hline & 12 & 23 & 6 & 20 & 4 & 21 & 6 & 21 & 6 & 22 & 1 & 23 & 10 & 28 & 4 & 24 & 1 & 20 & 4 & 25 \\
\hline & V & $T$ & V & $T$ & V & $T$ & $\mathrm{~V}$ & $T$ & $\mathrm{~V}$ & $T$ & V & $T$ & V & $T$ & V & $T$ & V & $T$ & V & $\mathrm{T}$ \\
\hline Ammonia parkinsoniana & & 0.2 & . & 0.1 & & 0.8 & & 2.8 & & & ${ }^{\circ}$ & & . & & 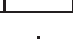 & & & & & \\
\hline Ammonia tepida & 3.1 & 11.8 & . & 8.1 & & 6.2 & 7.7 & 7.7 & 11.1 & 2.9 & . & 6.3 & & 3.8 & . & 3.8 & & 4.2 & & 2.0 \\
\hline Ammonia spp.* & . & 1.9 & & 0.2 & & 2.0 & & 2.0 & . & . & . & 4.7 & & 0.9 & . & 4.1 & . & 2.1 & & 0.3 \\
\hline Bolivina doniezi & . & 0.1 & . & . & & . & . & . & . & 1.4 & . & 0.6 & . & 0.7 & . & 0.3 & . & & & \\
\hline Bolivina ordinaria & 21.9 & 15.1 & 20.0 & 6.3 & 20.0 & 2.2 & 7.7 & 8.5 & 22.2 & 15.7 & . & 2.8 & 16.7 & 7.2 & . & 3.5 & & 1.4 & 20.0 & 2.0 \\
\hline Bolivina pulchella & 12.5 & 12.4 & 10.0 & 26.4 & 40.0 & 30.7 & & 22.2 & & 5.7 & 100.0 & 19.8 & 11.1 & 15.0 & 25.0 & 4.8 & 100.0 & 6.3 & 20.0 & 6.2 \\
\hline Bolivina sp. & . & & . & & & . & . & . & 11.1 & 1.4 & . & . & . & & . & . & . & & & \\
\hline Bolivina striatula & 6.3 & 2.5 & 20.0 & 3.2 & 20.0 & 4.2 & 15.4 & 12.9 & 11.1 & 1.4 & . & 2.6 & 11.1 & 7.0 & 25.0 & 2.2 & . & 2.8 & & 2.0 \\
\hline Buccella peruviana & . & . & & & & . & . & . & & . & . & & & & . & 1.9 & . & & & 0.7 \\
\hline Buliminella elegantissima & 35.9 & 19.9 & 20.0 & 10.3 & 20.0 & 9.6 & 38.5 & 13.7 & . & 1.4 & . & 3.4 & 27.8 & 8.5 & . & 6.3 & . & 5.6 & & 2.3 \\
\hline Cassidulina sp. & . & 1.8 & . & 7.3 & & 2.6 & & 1.2 & . & 2.9 & . & 6.7 & 5.6 & 5.8 & 25.0 & 6.0 & & 9.9 & 20.0 & 5.6 \\
\hline Cibicides variabilis & . & & & & & & . & . & & & . & . & . & & . & & . & & & 1.3 \\
\hline Discorbis williamsoni & . & 2.0 & . & 4.6 & & 0.8 & . & 2.0 & & 2.9 & . & 22.2 & . & 3.8 & . & 16.8 & . & 23.2 & & 15.7 \\
\hline Cribroelphidium discoidale & . & & . & 0.0 & & . & . & . & . & 1.4 & . & 0.9 & & 0.2 & . & 2.2 & . & 2.1 & & 4.2 \\
\hline Cribroelphidium poyeanum & . & 0.6 & . & 3.1 & & 1.6 & . & . & & 1.4 & . & 0.6 & & 0.7 & . & 3.8 & . & & & 3.6 \\
\hline Cribroelphidium sp. & . & 1.8 & . & 9.5 & & 5.4 & . & 3.6 & . & . & . & 8.2 & . & 8.3 & . & 8.6 & . & 13.4 & & 16.7 \\
\hline Cribroelphidium spp.* & 1.6 & 3.5 & . & 3.1 & & 8.0 & 7.7 & 5.2 & . & 2.9 & . & 5.4 & . & 5.8 & . & 3.5 & . & 1.4 & & 1.3 \\
\hline Fissurina semimarginata & . & 1.6 & . & 1.5 & & 3.4 & . & 0.4 & 11.1 & 2.9 & . & 1.7 & & 0.9 & . & 0.6 & & 2.8 & & 0.7 \\
\hline Fursenkoina pontoni & 1.6 & 0.7 & . & 0.1 & & 1.2 & . & 1.2 & . & . & . & 0.4 & 5.6 & 0.9 & . & . & . & 0.7 & & 0.3 \\
\hline Hopkinsina pacifica & . & 0.8 & . & 1.2 & & 0.8 & . & 0.8 & . & . & . & 0.4 & 5.6 & 1.8 & . & 8.9 & . & 3.5 & & 10.8 \\
\hline Miliolinella sp. & . & 0.2 & . & & & . & . & . & . & 8.6 & . & . & 5.6 & 2.2 & . & 0.3 & . & . & & 0.3 \\
\hline Oolina hexagona & . & & . & . & & . & . & 0.4 & . & . & . & 0.4 & . & 0.2 & . & . & . & . & & \\
\hline Pararotalia cananeiaensis & 3.1 & 9.3 & . & 2.0 & & 3.0 & & 5.2 & . & 1.4 & . & 2.8 & & 6.3 & 25.0 & 3.8 & & 2.1 & & 2.9 \\
\hline Patellina sp. & & 0.0 & . & & & & & & . & 1.4 & . & & & 0.2 & . & & & 0.7 & & \\
\hline Pseudononion atlanticum & 7.8 & 7.9 & 20.0 & 7.4 & & 12.9 & 15.4 & 6.0 & . & 8.6 & . & 4.7 & 5.6 & 9.2 & . & 9.2 & . & 8.5 & & 9.2 \\
\hline Pyrgo nasuta & . & 0.1 & . & & & . & . & . & . & . & . & 0.4 & & . & . & . & . & . & & \\
\hline Quinqueloculina lamarckiana & . & 0.0 & . & 0.0 & & . & . & . & . & 2.9 & . & . & & 0.7 & . & 0.6 & . & 2.1 & & 0.7 \\
\hline Quinqueloculina sp. & 3.1 & 2.2 & . & 2.7 & & 0.8 & $\cdot$ & 0.8 & & 7.1 & . & 0.2 & . & 2.7 & . & 2.2 & . & & 40.0 & 2.0 \\
\hline Rosalina floridana & . & 0.8 & . & 0.4 & & 0.6 & . & 0.8 & . & 14.3 & . & 0.4 & . & 2.2 & . & 0.6 & 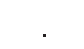 & & & \\
\hline Rosalina sp. & . & & . & & & . & . & & . & . & . & . & . & 0.2 & . & 0.3 & & 2.8 & & 3.6 \\
\hline Siphogenerina raphanus & . & . & . &. & & . & . & 0.8 & . & . & . &. & . & 0.4 & . & . & . & . & & \\
\hline Trochammina sp. & . & . & & & & . & . & . & & 1.4 & . & & & & . & . & . & & & . \\
\hline Uvigerina peregrina & $\cdot$ & & . & & & 0.2 & . & . & . & . & . & . & & & . & . & . & & & 0.7 \\
\hline Uvigerina sp. & 1.6 & & . & & & . & . & . & . & . & . & . & . & 0.2 & . & . & . & & & \\
\hline fragmentos & & 1.0 & . & 0.2 & & 1.2 & 7.7 & 0.8 & . & . & . & 1.3 & & 0.9 & . & 1.0 & & 2.8 & & 1.3 \\
\hline indeterminados & 1.6 & 2.0 & 10.0 & 2.3 & & 1.6 & & 0.8 & 33.3 & 10.0 & . & 2.8 & 5.6 & 3.1 & . & 4.4 & & 1.4 & & 3.9 \\
\hline
\end{tabular}

Cassidulina sp., Buccella peruviana) e Ammonia spp. apresentam porcentagens muito baixas.

\section{Composição faunística - Associação de vivos}

Carapaças vazias são mais numerosas que as coradas. As maiores densidades populacionais foram encontradas nas estações 1, 4 e 7 (13 a 64 ind/10 cc) (Figura 5A). Os locais mais ricos em espécies estão situados no lado leste (10 a 12 espécies) (Figura 5B). Os rotaliíneos são as formas dominantes, variando de 60 a $100 \%$ do total de vivos das amostras. Os miliolíneos só ocorrem na região do Lagosteiro e não foram encontrados textulariíneos vivos (Figura 5E-F).

Tanto nas associações compostas por carapaças mortas e vivas (Figura 4C) quanto nas associações de vivos (Figura 6C), constata-se que a espécie dominante é Bolivina (Tabela 1). O grupo das espécies indicadoras de ambiente rico em matéria orgânica atinge porcentagens mais expressivas próximo à desembocadura da enseada (Figura 6D), ao passo que as indicadoras de Água Tropical são mais abundantes nas porções internas (Figura 6G).

Dados morfométricos. De modo geral, há predomínio de carapaças médias por toda enseada (Figura 7). Carapaças 


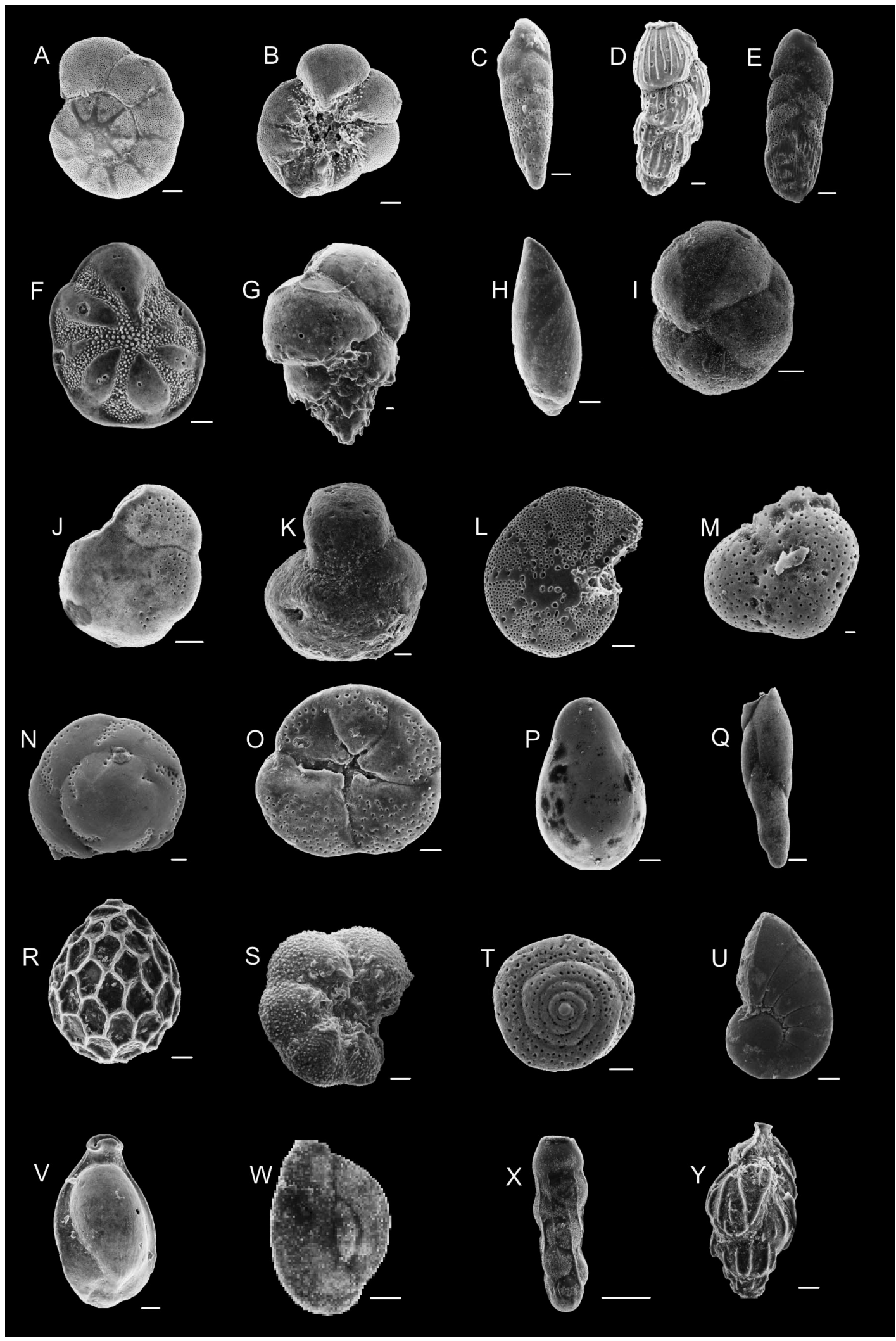

Figura 2. Foraminíferos da enseada do Flamengo. A, Ammonia tepida, lado espiral, $30 \mu \mathrm{m}$; B, Ammonia tepida, lado umbilical, $30 \mu \mathrm{m}$; C, Bolivina doniezi, $30 \mu \mathrm{m}$; D, Bolivina pulchella, $30 \mu \mathrm{m}$; E, Bolivina striatula, $20 \mu \mathrm{m}$; F, Buccella peruviana forma campsi, $30 \mu \mathrm{m}$; G, Bulimina

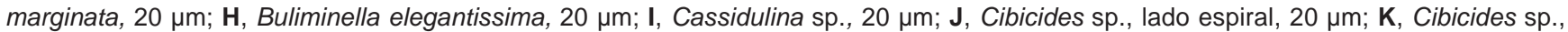
lado umbilical, $20 \mu \mathrm{m}$; L, Cribroelphidium discoidale, $30 \mu \mathrm{m}$; M, jovem de Cribroelphidium sp., $10 \mu \mathrm{m}$; N, Discorbis williamsoni, lado espiral, $20 \mu \mathrm{m} ; \mathbf{O}$, Rosalina floridana, lado umbilical, $20 \mu \mathrm{m} ; \mathbf{P}$, Fissurina semimarginata, $20 \mu \mathrm{m} ; \mathbf{Q}$, Fursenkoina pontoni, $30 \mu \mathrm{m} ; \mathbf{R}$, Oolina hexagona, $20 \mu \mathrm{m} ; \mathbf{S}$, Pararotalia cananeiaensis, $20 \mu \mathrm{m} ; \mathrm{T}$, Patellina sp., $20 \mu \mathrm{m}$; U, Pseudononion atlanticum, $30 \mu \mathrm{m} ; \mathbf{V}$, Pyrgo nasuta, 30 $\mu \mathrm{m}$; W, Quinqueloculina lamarckiana, $30 \mu \mathrm{m}$; X, Siphogenerina raphanus, $100 \mu \mathrm{m}$; Y, Uvigerina peregrina, $20 \mu \mathrm{m}$. Figure 2. Foraminifera of Flamengo Bay. 


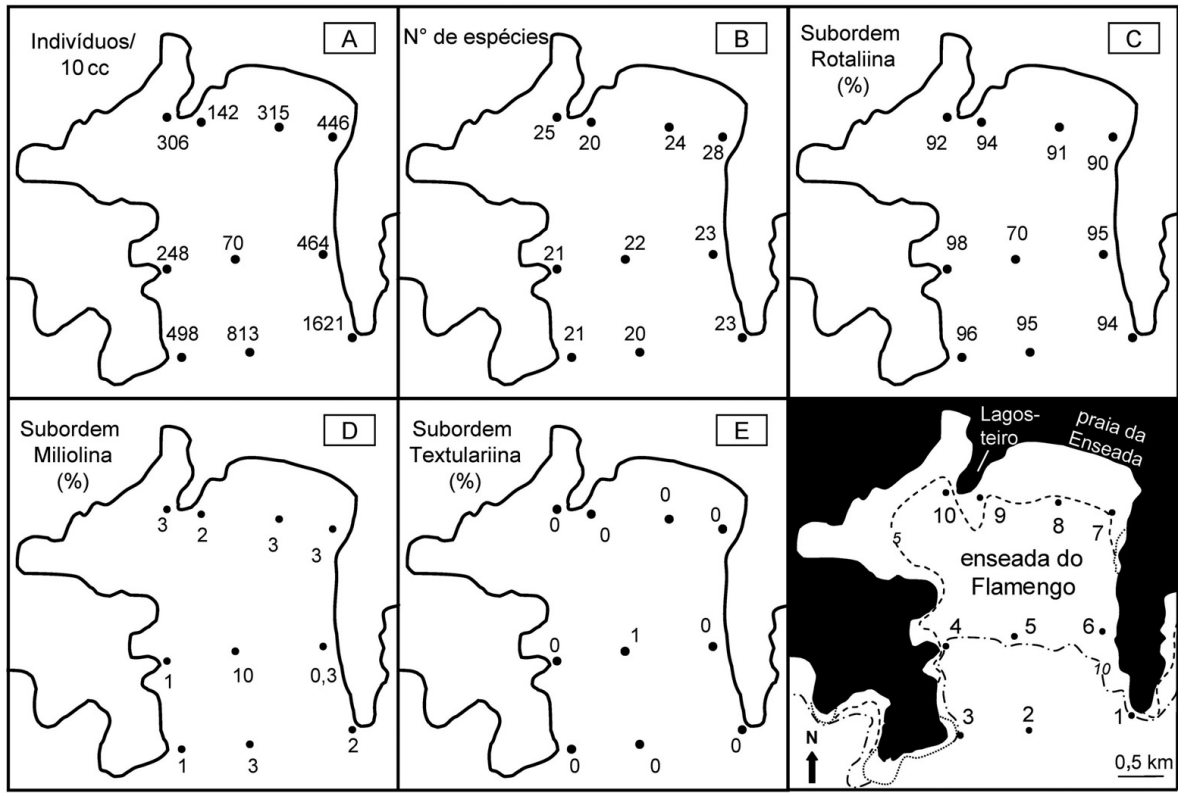

Figura 3. Parâmetros populacionais (densidade e riqueza) e freqüência relativa das principais subordens de foraminíferos (dados referentes à associação total).

Figure 3. Density, number of species and relative abundance of living and dead Rotaliina, Miliolina and Textulariina.

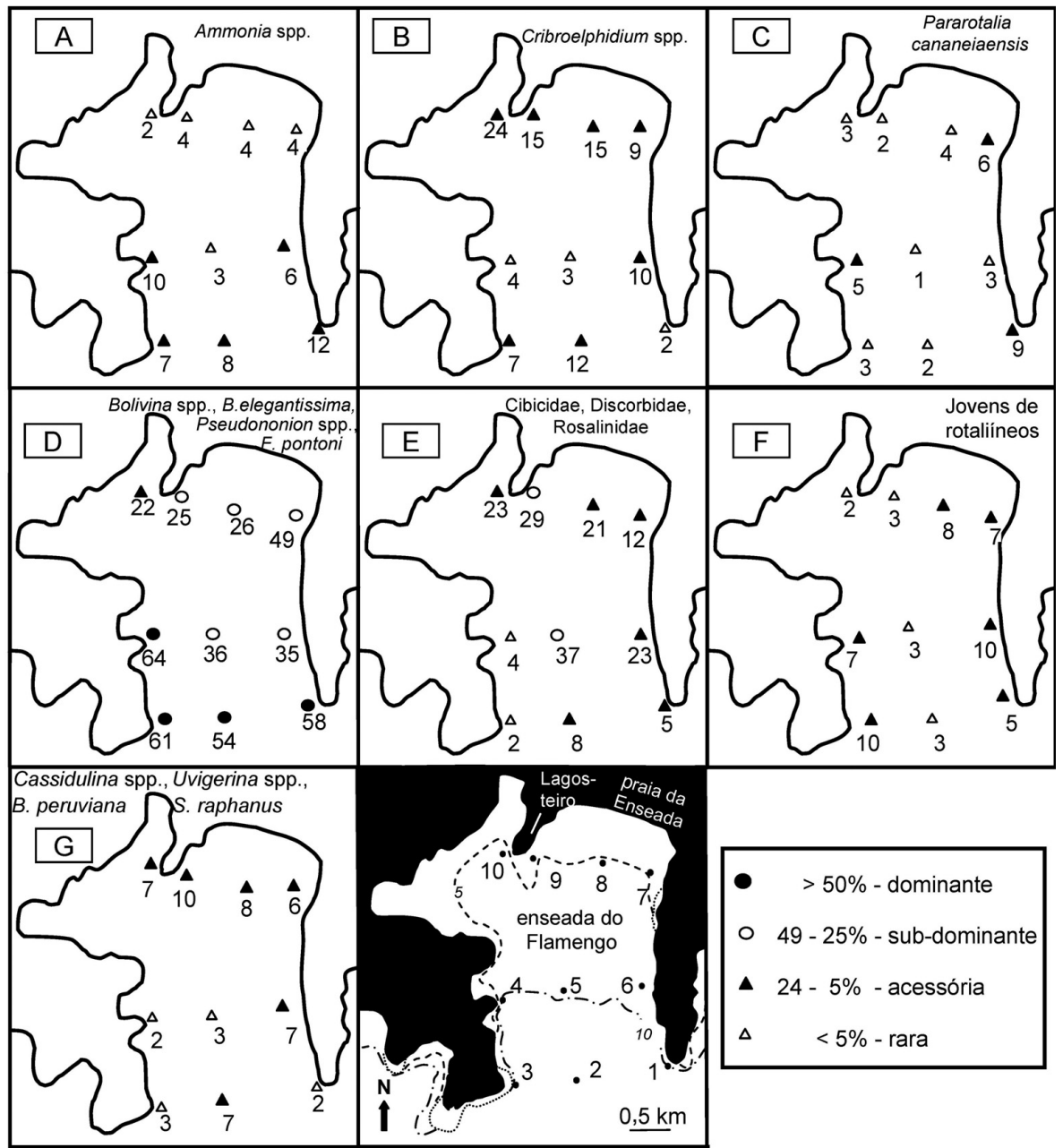

Figura 4. Mapa de distribuição das espécies indicadoras de Água Costeira (A-D), de Água Tropical (G), de sedimentos ricos em matéria orgânica (D), de ambientes com circulação hidrodinâmica moderada a forte (E) e de ambientes com circulação hidrodinâmica baixa (F) (baseado na freqüência relativa da associação total).

Figure 4. Distribution map of living and dead foraminifera showing the relative abundance of species indicative of Coastal Water (A-D), Tropical Water $(\mathbf{G})$, organic-rich sediments $(\mathbf{D})$, moderate to strong hydrodynamic circulation $(\mathbf{E})$ and low hydrodynamic environment $(\mathbf{F})$. 
grandes também estão amplamente distribuídas, contudo são mais abundantes na porção central e leste da enseada (estações 1, 2, 5, 6). Não foram encontradas carapaças muito grandes, i.e., maiores que $500 \mu \mathrm{m}$. Carapaças pequenas são progressivamente mais numerosas rumo às porções internas da enseada. Por exemplo, na região da desembocadura, a quantidade de carapaças pequenas é irrisória, mas na região próxima ao saco do Perequê Mirim chegam atingir $18 \%$ do total da amostra (Figura 7).

Dados tafonômicos. A análise tafonômica das carapaças permitiu identificar testas calcárias com sinais de abrasão (desgaste mecânico) e de bioerosão, bem como corroídas (desgaste químico) (Figuras 8 a 10). As porcentagens de carapaças total ou parcialmente fragmentadas são baixas, sendo ligeiramente mais elevadas próximo à zona de arrebentação de ondas da praia da Enseada (Figura 8). Todas as amostras apresentaram exemplares corroídos (Figuras 9 e 10).

Carapaças preenchidas por monossulfeto de ferro ou por matéria orgânica são mais abundantes nas porções internas da enseada (Tabela 2). Carapaças limonitizadas são mais numerosas próximo à desembocadura.

\section{DISCUSSÃO}

A porção leste da enseada apresenta maior quantidade de indivíduos e número de espécies de foraminíferos que as porções oeste e central. Esse padrão de distribuição é observado para as associações total (i.e., mortos e vivos) e de vivos. Espécies típicas de Água Costeira (Ammonia spp., Buliminella elegantissima, Pseudononion spp.) dominam toda enseada. Dentre estas, as espécies indicadoras de ambiente rico em matéria orgânica são dominantes, chegando a atingir mais de $50 \%$ do total de cada amostra. Apesar de raras, espécies indicadoras de Água Tropical (e.g., Uvigerina peregrina, Siphogenerina raphanus) e da epifauna (espécies de Cibicidae, Discorbidae e Rosalinidae) são encontradas vivas na desembocadura e na porção nordeste da enseada (e.g., praia da Enseada, região do Lagosteiro). Tais resultados indicam a predominância de Água Costeira por toda enseada, com intrusões de massas de água da plataforma externa nas porções mais internas da enseada. Esses dados estão de acordo com os dados hidrográficos apresentados em Gonsalves et al. (1980) e Mahiques (1992). A dominância de Buliminella elegantissima, Bolivina spp. e Pseudononion spp., bem como a presença de organismos da epifauna sugere que enseada do Flamengo é um ambiente com dinâmica de fundo moderada a baixa, que permite o acúmulo de matéria orgânica. Essas interpretações coadunam com os trabalhos sobre dinâmica sedimentar realizados na enseada (cf. Magliocca \& Kutner, 1965; Mahiques, 1992, 1995; Mahiques et al., 1998). De acordo com esses autores, há predomínio de sedimentos siltosos por toda enseada, com teores de carbono orgânico superior a $1 \%$ (lado oeste).

A dominância de carapaças médias, a ocorrência de várias carapaças grandes, bem como a presença pouco conspícua de carapaças pequenas nas regiões de desemboca- dura e central permitem inferir que a energia hidrodinâmica da enseada do Flamengo deve ser moderada. As carapaças pequenas devem estar em suspensão e tendem a se depositar nas regiões mais confinadas da enseada (i.e., saco da Ribeira). Dados de correntometria de Mahiques (1992) dão suporte a esta interpretação, revelando correntes sempre abaixo de $10 \mathrm{~cm} / \mathrm{s}$, excetuando os períodos de passagens de frentes frias, onde a velocidade das correntes ultrapassam $20 \mathrm{~cm} / \mathrm{s}$. Esta velocidade, de acordo com o diagrama de Hjulström (Friedman \& Saunders, 1978), é suficiente para manter partículas de quartzo de $4 \varnothing(=62 \mu \mathrm{m})$ em suspensão. Como carapaças de foraminíferos apresentam uma série de características (e.g. poros, espículas, formas pouco angulosas, câmaras cheias de ar) que as tornam mais leves que um grão de quartzo (Martin, 1999a), pressupõe-se que a velocidade de $10 \mathrm{~cm} / \mathrm{s}$ é mais que suficiente para manter foraminíferos de até $125 \mu \mathrm{m}$ em suspensão (Murray et al., 1982; Murray, 2003).

As porcentagens de carapaças total ou parcialmente fragmentadas são baixas, contudo são ligeiramente mais elevadas próximos à zona de arrebentação de ondas da praia da Enseada. Isto sugere que a energia hidrodinâmica não deve ser muito alta, a ponto de transportar partículas muito grandes, arrastando-as pelo fundo e quebrando-as.

Apesar de não ser possível quantificar as carapaças corroídas em microscópio estereoscópio, pode-se detectá-las em todas as amostras analisadas em microscópio eletrônico de varredura. Em ambiente marinho, carapaças calcárias podem ser maceradas ou dissolvidas, devido à subsaturação

Tabela 2. Freqüência absoluta das carapaças preenchidas por monossulfeto de ferro (MF), matéria orgânica (MO) e normais (N) encontradas na enseada do Flamengo. As carapaças normais não possuem preenchimento nem coloração.

Table 2. Absolute abundance of the tests filled by iron monosulphide (MF) and organic matter (MO) and regulars (N) collected in the Enseada do Flamengo. Regular tests do not present filling or color.

\begin{tabular}{|c|c|c|c|c|}
\hline \multirow{2}{*}{ 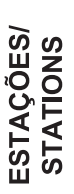 } & \multicolumn{4}{|c|}{ CARAPAÇAS/TESTS } \\
\hline & $\mathbf{L}$ & MF & MO & $\mathbf{N}$ \\
\hline 1 & 2 & 12 & 2 & 1605 \\
\hline 2 & 3 & 2 & 2 & 806 \\
\hline 3 & 3 & 4 & 1 & 490 \\
\hline 4 & 2 & 3 & 0 & 243 \\
\hline 5 & 0 & 1 & 0 & 69 \\
\hline 6 & 0 & 5 & 2 & 457 \\
\hline 7 & 0 & 4 & 1 & 441 \\
\hline 8 & 0 & 6 & 7 & 302 \\
\hline 9 & 0 & 1 & 3 & 138 \\
\hline 10 & 1 & 5 & 8 & 292 \\
\hline
\end{tabular}




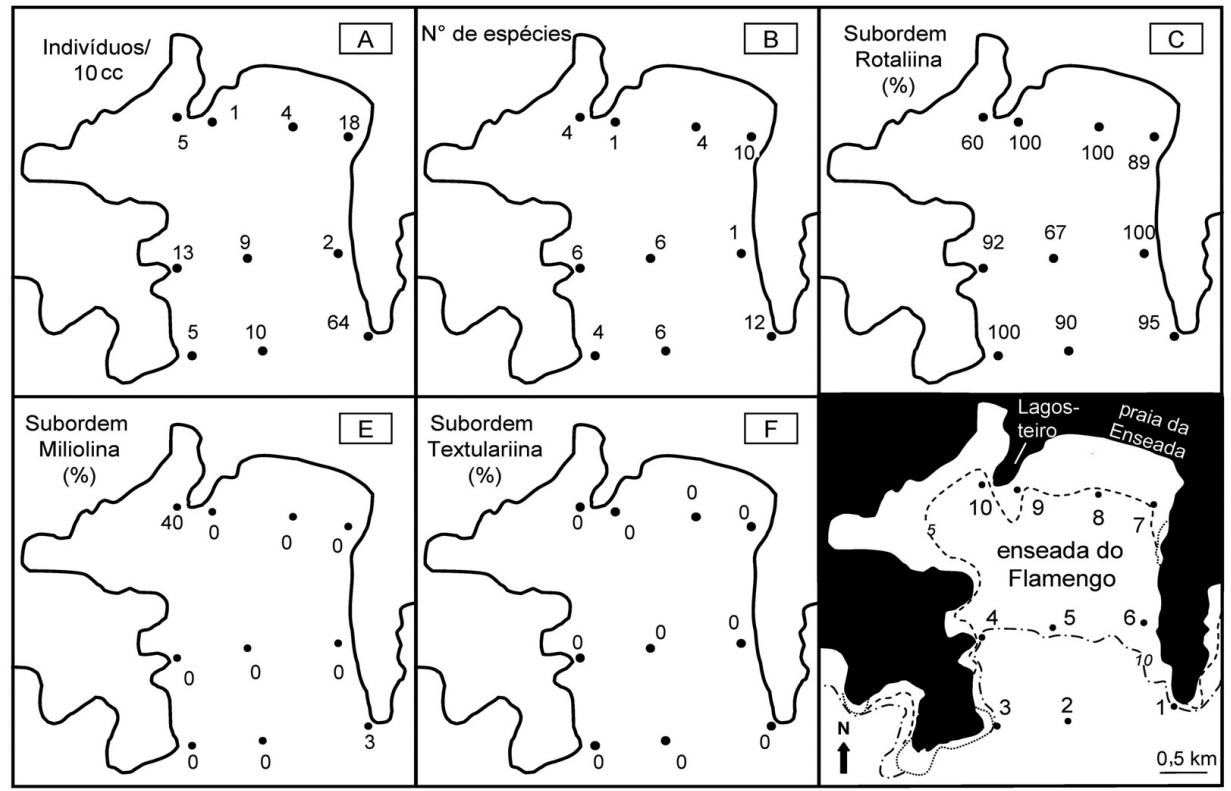

Figura 5. Parâmetros populacionais (densidade e riqueza) e freqüência relativa das principais subordens de foraminíferos (dados referentes à associação de vivos).

Figure 5. Density, number of species and relative abundance of living Rotaliina, Miliolina and Textulariina.

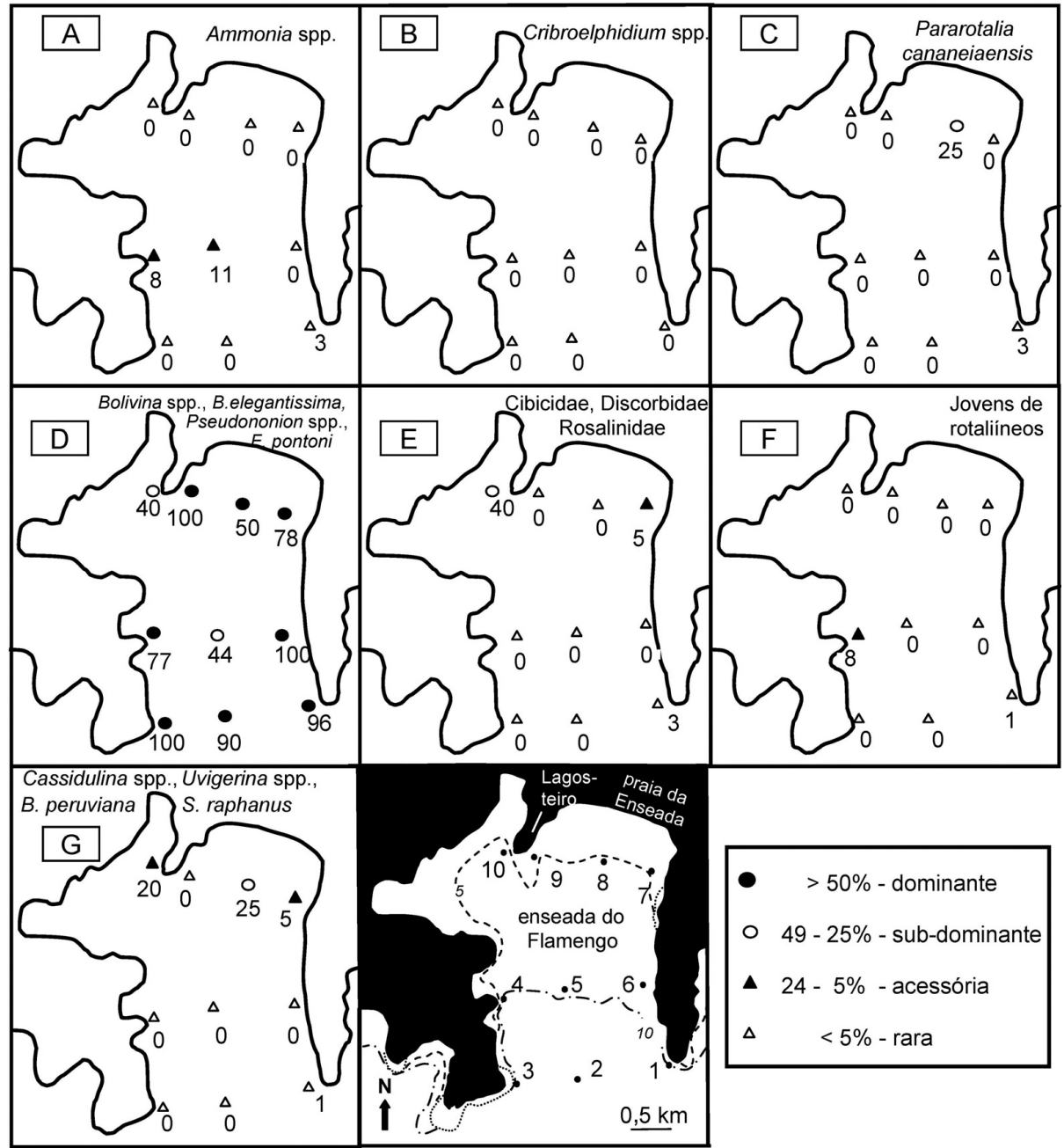

Figura 6. Mapa de distribuição das espécies indicadoras de Água Costeira (A-D, F), de Água Tropical (G), de sedimentos ricos em matéria orgânica (D), e da epifauna (E) (baseado na freqüência relativa da associação de vivos).

Figure 6. Distribution map of living foraminifera showing the relative abundance of species indicative of Coastal Water $(\mathbf{A}-\mathbf{D}, \mathbf{F})$, Tropical Water (G), organic-rich sediments (D), and epifauna (E). 


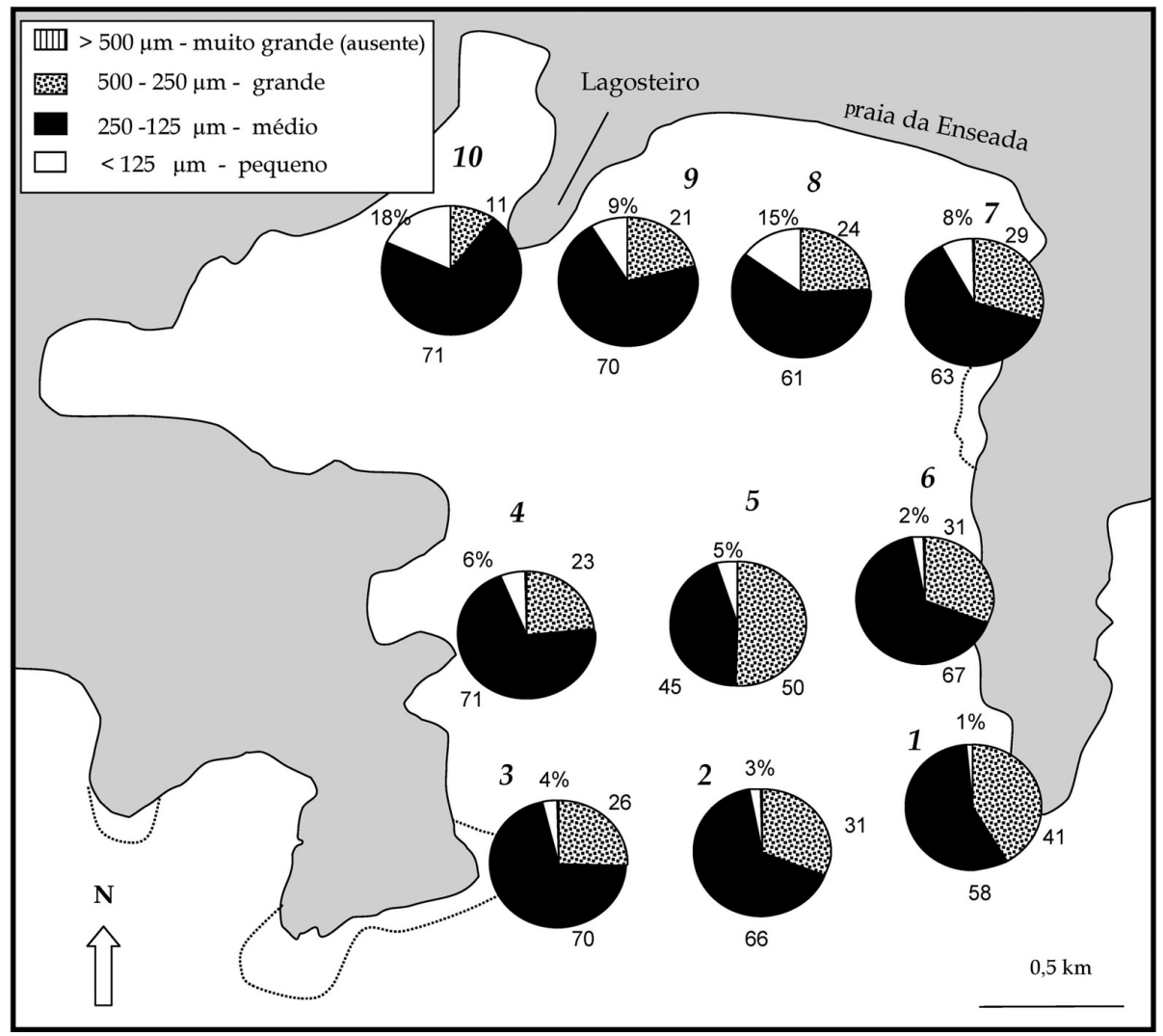

Figura 7. Tamanho das carapaças dos foraminíferos da enseada do Flamengo.

Figure 7. Morphometric data of the tests.

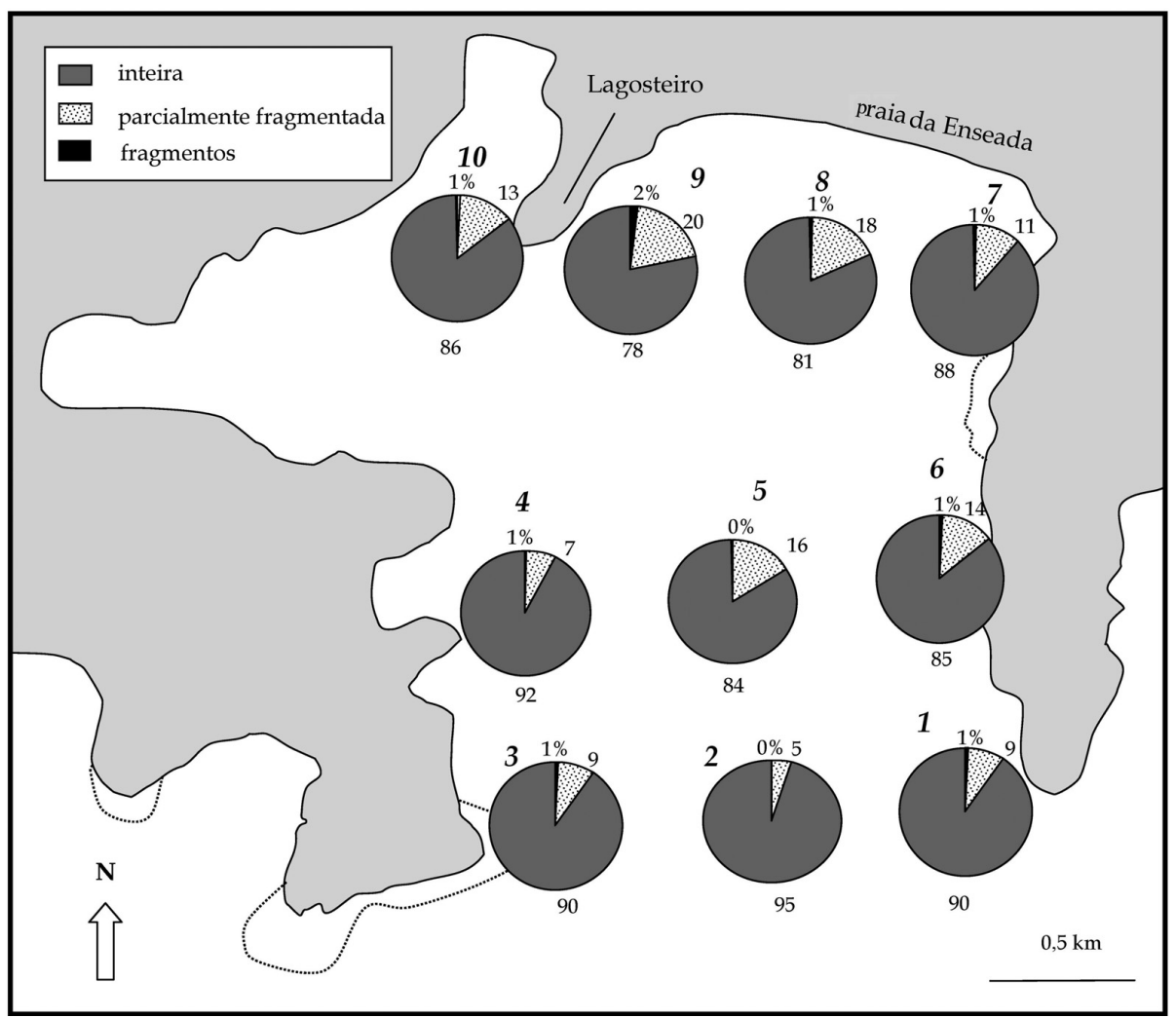

Figura 8. Estado de conservação das carapaças de foraminíferos da enseada do Flamengo. Figure 8. Taphonomic state of foraminifera tests. 


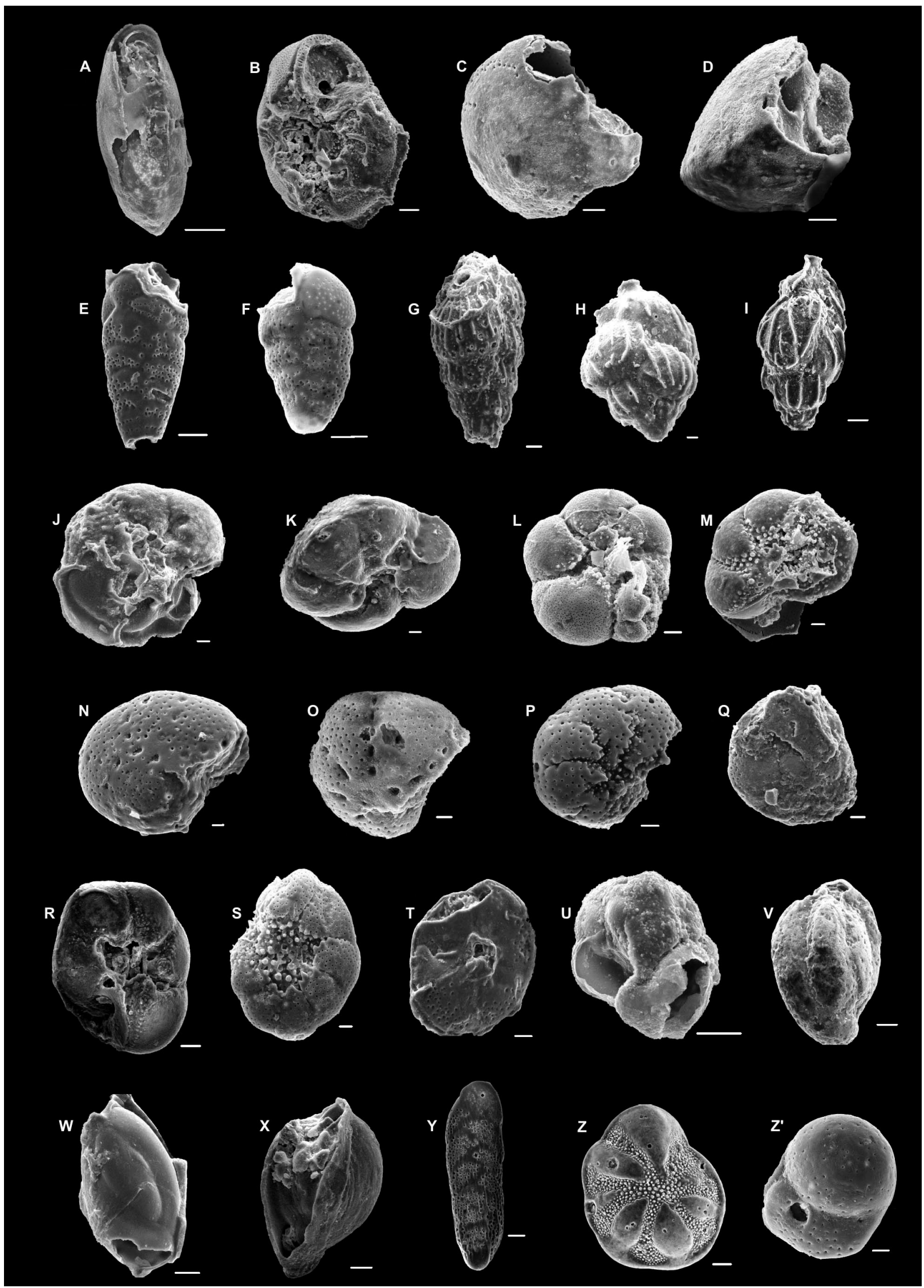

Figura 9. Fotomicrografias ilustrando o estado de conservação das carapaças da enseada do Flamengo. Escala: $20 \mu \mathrm{m}$. A-X, carapaças corroídas (excetuando $\mathbf{E}$ e $\mathbf{F}$ ); $\mathbf{E}-\mathbf{F}$, carapaças fragmentadas; $\mathbf{Y}-\mathbf{Z}^{\prime}$, carapaças bioerodidas.

Figure 9. SEM photomicrographs of tests from Flamengo Bay. A-X, dissolved tests - decalcification process (except $\mathbf{E}$ and $\mathbf{F}$ ); $\mathbf{E}-\mathbf{F}$, broken tests; Y-Z', bioeroded tests. 


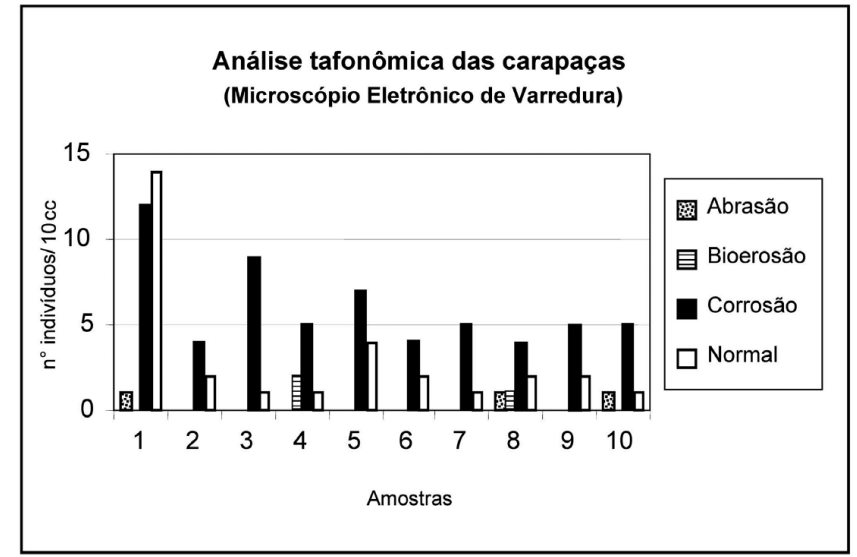

Figura 10. Freqüência relativa das carapaças erodidas, bioerodidas, corroídas e normais, analisadas em microscópio eletrônico de varredura.

Figure 10. Relative abundance of eroded, bioeroded, dissolved and normal tests.

de carbonato de cálcio na água (Alexandersson, 1979; Berger, 1979) ou podem ser corroídas por meio da ação direta ou indireta de bactérias anaeróbicas presentes no sedimento (Gröbe \& Fütterer, 1982). No tocante às bactérias, estas podem atacar diretamente a matriz orgânica que dá sustentação aos cristais de calcita nas carapaças (Gröbe \& Fütterer, 1982), ou indiretamente, liberando substâncias nos sedimentos, acidificando o meio, resultando também na desorganização dos cristais das carapaças. No caso da enseada do Flamengo, como suas águas são saturadas de carbonato de cálcio, é mais provável que as carapaças corroídas sejam produto de ação bacteriana, devido às características fortemente redutoras do ambiente.

Esses resultados, aliados à presença de carapaças preenchidas por monossulfeto de ferro (que só se precipita em ambiente redutor, cf. Duleba, 1994), indicam mais uma vez que enseada do Flamengo é ambiente com energia de fundo moderada, com tendência a assumir características redutoras. Considerando-se que foraminíferos bentônicos encontrados atualmente na Enseada do Flamengo ocorrem em ambientes de plataforma interna desde o Cenozóico e que o padrão de distribuição destes organismos é condicionado por padrões de circulação de fundo e por massas de água dominantes, acredita-se que os dados aqui apresentados podem ser úteis como análogos para inferências paleoambientais.

\section{CONCLUSÕES}

A partir da distribuição espacial dos foraminíferos e da análise morfométrica, morfológica e tafonômica de suas carapaças, pode-se concluir que a enseada do Flamengo é um ambiente dominado por Água Costeira, com energia hidrodinâmica moderada, a qual tende a diminuir gradativamente em direção ao continente, desde a desembocadura Excetuando a praia da Enseada, as porções mais internas apresentam-se como subambientes de baixa energia deposicional e de circulação restrita.

\section{AGRADECIMENTOS}

Os autores agradecem ao CNPq pela bolsa de iniciação científica (RLB) e à FAPESP (Proc. 02/026110-2) pelo suporte financeiro. A Isaac J.Sayeg (IGcUSP) e Marcos Mansueto (IGcUSP) pelas fotomicrografias dos foraminíferos; a Andréia C.Teodoro, Paulo H. S. Lombardo pelo auxílio nas sessões de morfometria; e a Alexandre Bittencourt, Sílvia Santos e Thomas Rich Fairchild pela revisão do inglês. Aos assessores Carla Bonetti e Ana Luisa Carreño pela cuidadosa revisão do manuscrito.

\section{REFERÊNCIAS}

Alexandersson, E.T. 1979. Marine maceration of skeletal carbonates in Skagerrak, North Sea. Sedimentology, 26:845852.

Berger, W. 1979. Preservation of Foraminifera. American Association of Petroleum Geologist, SEMP Short Course, 6:105-155.

Bernhard, J.M. 1986. Characteristics assemblages and morphologies of benthic foraminifera from anoxic, organicrich deposits: Jurassic through Holocene. Journal of Foraminiferal Research, 16:207-215.

Boltovskoy, E. 1958. Foraminifera as biological indicators in the study of ocean currents. Micropaleontology, 5:473-481.

Boltovskoy, E.; Giussani, G.; Watanabe, S. \& Wright, R. 1980. Atlas of benthic shelf foraminifera of southwest Atlantic. Netherlands, Dr. W. Junk, 147 p.

Debenay, J.P. \& Guilou, J.J. 2002. Ecological transitions indicated by Foraminiferal assemblages in paralic environment. Estuaries, 25:1107-1120.

Duleba, W. 1993. Variações nas associações de foraminíferos ao longo da coluna sedimentar da Enseada do Flamengo, Ubatuba, SP. Instituto Oceanográfico, Universidade de São Paulo, Dissertação de Mestrado, 210 p.

Duleba, W. 1994. Interpretações paleoambientais obtidas a partir das variações na coloração das carapaças de foraminíferos da Enseada do Flamengo, SP. Boletim do Instituto Oceanográfico, 42:63-72.

Duleba, W.; Coimbra, J.C.; Petri, S. \& Barbosa, C. F. 2005. Foraminíferos, tecamebas e ostracodes recentes utilizados como bioindicadores em estudos ambientais brasileiros. In: C.R.G. Sousa; K. Suguio; M. Santos \& P.E. Oliveira (eds) Quaternário do Brasil. ABEQUA. Ribeirão Preto, Editora Holos, p. 176-210.

Friedman, G. M. \& Saunders, J. E. 1978. Principles of sedimentology. New York, Wiley, 792 p.

Gonsalves, M.S.; Ito, R.G.; Nishihara, L; Pinheiros, E.A.; Tavares, W. Jr.; Ambrosio, O, Jr. \& Iokles, I. 1980. Propriedades físicas e químicas em dois pontos fixos na Enseada do Flamengo, Ubatuba, SP. Boletim do Instituto Oceanográfico, 29:9-18.

Gröbe, H. \& Fütterer, D. 1982. Zür fragmentierung benthischer Foraminiferen in der Kieler Bucht (Westkiche Ostsee). Meyniana, 33:85-96.

Hallock, P.; Forward, L.B. \& Hansen, H.J. 1986. Influence of environment on the test shape of Amphistegina. Journal of Foraminiferal Research, 16:224-231.

Hendrix, W.E. 1958. Foraminiferal shell form, a key to sedimentary environment. Journal of Paleontology 32:649-659.

Loeblich, A.R. \& Tappan, H. 1964. Part C, Protista 2, Sarcodina, 
chiefly "Thecamoebians" and Foraminiferida. In: R.C. Moore (ed.) Treatise on invertebrate paleontology, The University Kansas Press, 2 v., 900 p.

Loeblich, A.R. \& Tappan, H. 1988. Foraminiferal genera and their classification. New York, Van Nostrand, p. C1-C900.

Magliocca, A. \& Kutner, A.S. 1965. Sedimentos de fundo da Enseada do Flamengo - Ubatuba. Boletim do Instituto Oceanográfico, Física, 8:1-14.

Mahiques, M.M. 1992. Variações temporais na sedimentação holocênica dos embaiamentos da região de Ubatuba (SP). Instituto Oceanográfico, Universidade de São Paulo, Tese de Doutorado, $352 \mathrm{p}$.

Mahiques, M.M. 1995. Dinâmica sedimentar atual nas enseadas da região de Ubatuba, Estado de São Paulo. Boletim do Instituto Oceanográfico, 43:111-122.

Mahiques, M.M.; Tessler, M.G. \& Furtado, V.V. 1998. Characterization of energy in enclosed bays of Ubatuba region, south-eastern Brazil. Estuarine, Coastal and Shelf Science, 47:431-446.

Martin, R. 1999a. Taphonomy a process approach. Cambridge, Cambridge University Press, 508 p.

Martin, R.E. 1999b. Taphonomy and temporal resolution of foraminiferal assemblages. In: B.K. Sem Gupta (ed.) Modern foraminifera. Kluwer Academic Press, p. 281-298.

Murray, J.W. 1991. Ecology and palaeoecology of benthic foraminifera. London, Longman Scientific \& Technical, 397 p.
Murray, J.W. 2003. Foraminiferal assemblage formation in depositional sinks on the continental shelf west of Scotland. Journal of Foraminiferal Research, 33:101-122.

Murray, J.W.; Sturrock, S. \& Weston, J. 1982. Suspended load transport of foraminiferal tests in a tide and wave-swept sea. Journal of Foraminiferal Research, 12:51-65.

Seiglie, G. A. 1968. Foraminiferal assemblage as indicator of high organic carbon content in sediments and of pollutes waters. Bulletin of American Association of Petroleum Geologist, 52:2231-2241

Schnitker, D. 1974. Western Atlantic abyssal circulation during the past 12,000 years. Nature, 248:385-387.

Schröder, C.J.; Scott, D.B. \& Medioli, F.S. 1987. Can smaller benthic foraminifera be ignored in paleoenvironmental analyses? Journal of Foraminiferal Research, 4:101-110.

Scott, D.B.; Medioli, F.S.; Schaffer, C.T. 2001. Monitoring in Coastal Environments using Foraminifera and Thecamoebian Indicators. Cambrigde, Cambridge University Press, $177 \mathrm{p}$.

Yordanova, E.K. \& Hohenegger, J. 2002. Taphonomy of larger foraminifera: relationships between living and empty tests on flat reef slopes (Sesoko Island, Japan). Facies, 46:169-204.

Walton, W.R. 1952. Techniques for recognition of living foraminifera. Contribution of Cushman Fundation for Foraminiferal Research, 3:56-60.

Received December, 2004; accepted July, 2005. 